Supplement of Geosci. Model Dev., 10, 3481-3498, 2017

https://doi.org/10.5194/gmd-10-3481-2017-supplement

(C) Author(s) 2017. This work is distributed under

the Creative Commons Attribution 3.0 License.

(c) (1)

Supplement of

\title{
An improved land biosphere module for use in the DCESS Earth system model (version 1.1) with application to the last glacial termination
}

Roland Eichinger et al.

Correspondence to: Roland Eichinger (roland.eichinger@dlr.de, roland@dgf.uchile.cl)

The copyright of individual parts of the supplement might differ from the CC BY 3.0 License. 


\section{S1 Introduction}

This supplement provides additional material to the article "An improved land biosphere module for use in reduced complexity ESMs with application to the last glacial termination". We provide a detailed description of our treatment of the dust radiative forcing and high latitude ocean iron-limitation and present an example case for the snow and ice line parameterisation that 5 interacts with the new biosphere scheme. Next, we give the mathematical description of the ocean vertical diffusion profile function in the high latitude model ocean that is applied for generating Last Glacial Maximum (LGM) conditions in the DCESS model and the formulation of the resumption of deep ocean mixing. Furthermore, we present some additional information on the generation of model LGM conditions in atmosphere and ocean, a literature review on the Mystery Interval (MI) and some additional sensitivity simulations. The Supplement ends with additional information on the various ${ }^{14} \mathrm{C}$ production rate time

10 series that were applied in the model simulations, an analysis of the DCESS model calculated ${ }^{14} \mathrm{C}$ production rate time series and the isotope ratio definitions. 


\section{S2 Transition function for dust concentration}

As described in the manuscript, the dustier atmosphere during LGM climate conditions (e.g. Maher et al. 2010) leads to cooling as forced by an additional radiative forcing $\left(A_{D u s t}\right)$ of $-1 \mathrm{Wm}^{2}$ (see Mahowald et al. 2006) and increased iron-fertilization, addressed in the model by an increased efficiency factor $\left(f_{F e-l i m}\right)$ in the high latitude ocean (Lambert et al., 2013, 2015). For

5 the transition of these parameters between LGM and PI conditions in the transient simulations, we applied functions derived from the correlation between dust flux and global mean atmosphere temperatures in proxy data records. Fig. S1 shows proxy data records from Antarctica of dust flux and temperature (Jouzel et al., 2007; : Lambert et al., 2012). As stated in Lambert et al. (2012), the major changes in dust flux occurred before $15 \mathrm{kaBP}$. An analysis of the correlation of the two quantities yields an exponential dependency of dust with temperature for both high and low latitudes that can be described by

$10 A_{\text {Dust }}=a \cdot e^{-0.4 \cdot T_{\text {glob }}}+b$,

where $\mathrm{a}$ and $\mathrm{b}$ are constants to be determined.. The same climate-dust exponential relationship also holds true for a remote site from the central Pacific (Winckler et al., 2008).

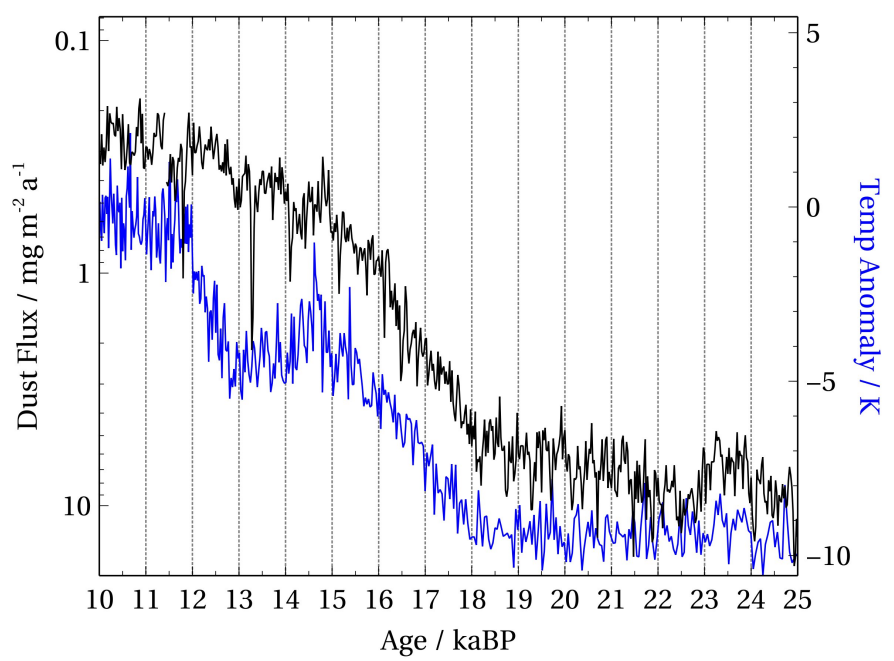

Figure S1. Dust fluxes and Antarctic temperature anomaly across the last glacial termination (Jouzel et al., 2007, Lambert et al., 2012). 

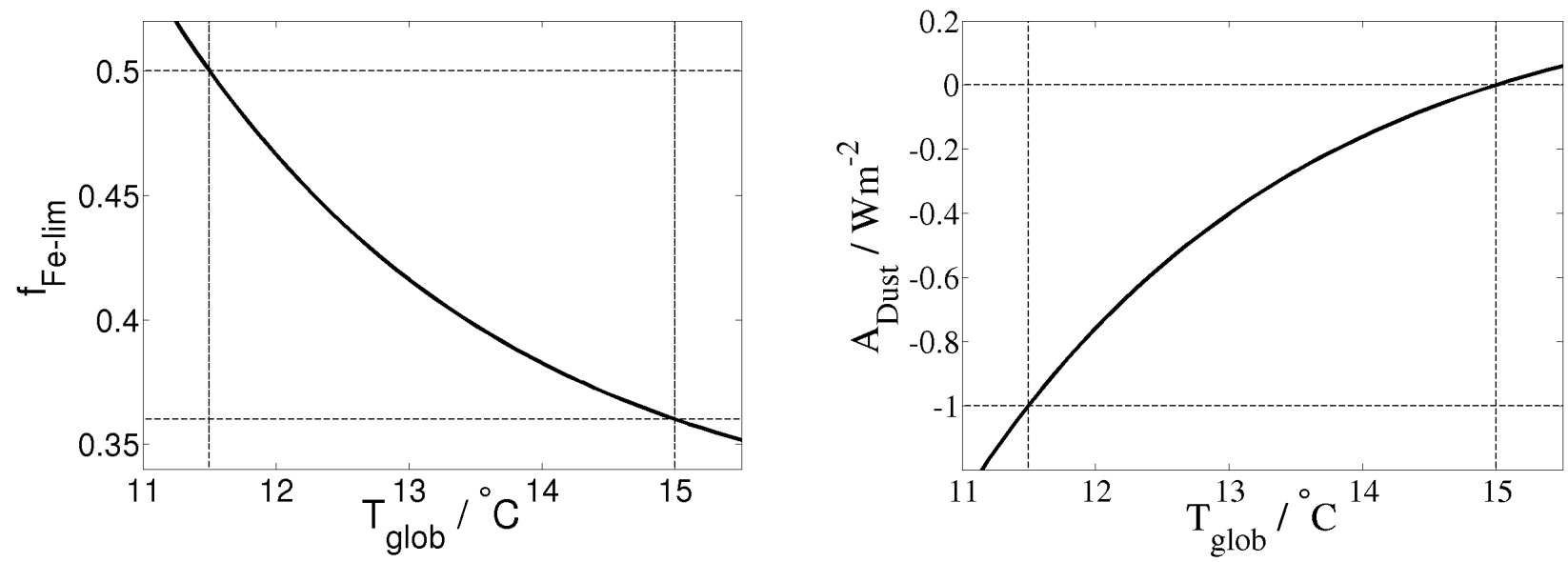

Figure S2. Transition functions for iron-limitation factor $f_{F e-l i m}$ (left panel) and for additional radiative forcing $A_{D u s t}$ due to dust (right panel) variations between LGM and PI.

This relationship provides a relatively simple approach for the temperature-dependent transition functions of $A_{D u s t}$ and $f_{\mathrm{Fe}-\mathrm{lim}}$ from LGM to PI conditions. For this, we use the conditions $f_{\mathrm{Fe}-\mathrm{lim}}=0.36$ for $\mathrm{PI}\left(T_{\text {glob }}=15^{\circ} \mathrm{C}\right)$ and $f_{\mathrm{Fe}-\mathrm{lim}}=0.5$ (see manuscript) for LGM $\left(T_{g l o b}=11.5^{\circ} \mathrm{C}\right)$ and $A_{D u s t}=0$ for PI and $A_{D u s t}=-1$ for LGM. With the function $a \cdot e^{-0.4 \cdot T_{g l o b}}+$ $b$ for the correlation between $T_{g l o b}$ and dust flux during this period derived from proxy data, the transition functions

$5 \quad f_{F e-\lim }=\frac{0.14 \cdot e^{-0.4 \cdot T_{g l o b}}+0.36 \cdot e^{-4.6}-0.5 \cdot e^{-6}}{e^{-4.6}-e^{-6}}$

for the iron limitation factor and

$A_{\text {Dust }}=\frac{-e^{-0.4 \cdot T_{\text {glob }}}+e^{-6}}{e^{-4.6}-e^{-6}}$

for the additional dust radiative forcing can be established. In Fig. $\mathrm{S} 2$, these functions are plotted for the range of $\mathrm{T}_{\text {glob }}$ considered here. 


\section{S3 Snow and ice line example case}

Fig. S3 shows the ice sheet line (converted as described in the manuscript from the data by Shakun et al., 2012) and the snowline (latitude of zonal mean atmospheric $T=0^{\circ} \mathrm{C}$ ) as calculated by the transient model simulation with all transition functions (the REF simulation) from Sect. 3.2. The thick parts of the lines mark the current minimum of the two functions, which is the value that is applied in the calculations at the actual time step (see Sect. 2.3). This means that in this simulation, the ice sheet line

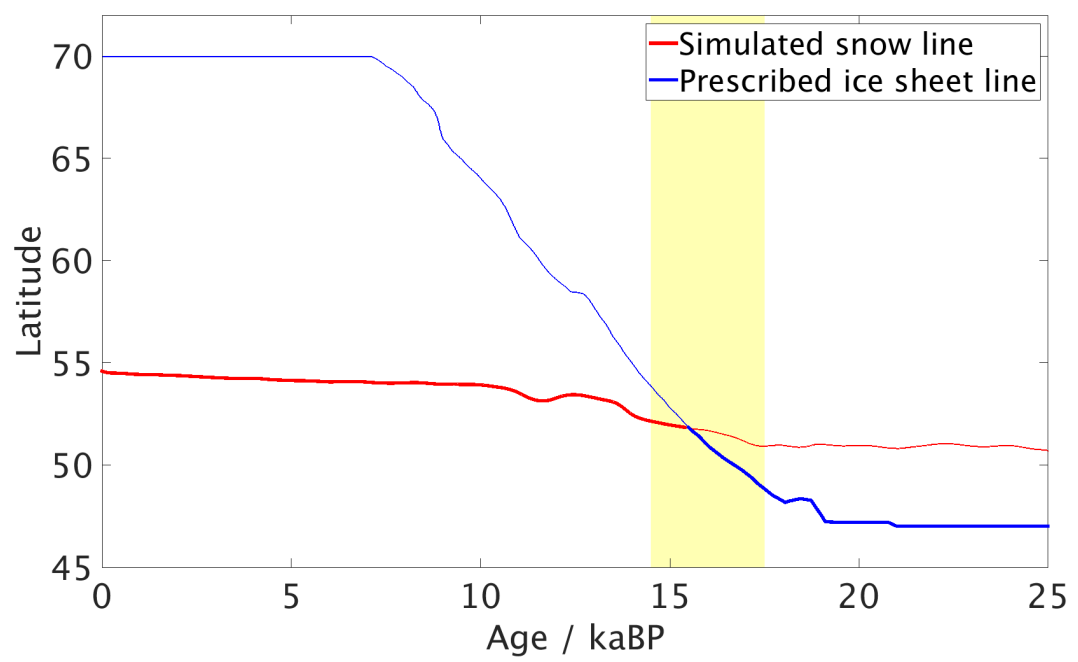

Figure S3. DCESS model-calculated "snowline" (red, from the REF simulation in Fig. 5) and prescribed line of NH ice sheet expansion (blue) converted as described in the text from data by Shakun et al. (2012). The current minimum of the two lines (thick) is used for the calculation of the albedo and the vegetation extent. The yellow shading marks the period of the MI.

5

has no influence on the results between 0 and $16 \mathrm{kaBP}$ and the same is true for the snowline between 16 and $25 \mathrm{kaBP}$. Due to the transition of the minimum between the functions at around $16 \mathrm{kaBP}$, some results may show a kink there.

The equatorward displacement of the model snowline and the expansion of terrestrial ice sheets lead to three important vegetation-climate feedbacks in this DCESS model version. Firstly, they influence the calculation of the global land albedo, leading to a positive cooling feedback. Secondly, they limit the poleward expansion of the EF vegetation zone. This decreases the carbon uptake of the vegetation and thus leads to an atmospheric $p \mathrm{CO}_{2}$ increase and a negative cooling feedback. Thirdly, increased land coverage by the ice sheets leads to more carbon storage in permafrost and a second positive cooling feedback. 


\section{S4 Ocean vertical diffusion profile}

In the article we present a profile for the high latitude ocean vertical diffusion with depth, which is applied to generate an analogy to isolated Southern Ocean (SO) deep and intermediate waters (see e.g. Watson and Naveira Garabato, 2006). In this section, we present details about this profile and explain how it was established. The mathematical formulations of the profile

5 and of the resumption to full vertical diffusion in the transient simulations are given.

\section{S4.1 Description of the profile}

For PI climate conditions, the ocean vertical diffusion parameter is set to $D_{P I}=2.3 \cdot 10^{-3} \mathrm{~m}^{2} \mathrm{~s}^{-1}$ evenly throughout the high latitude DCESS model ocean. To generate isolated deep water and thereby LGM climate conditions, we impose the function

$D_{p}=\left[\left(0.5 \cdot \tanh \left(-d \cdot 0.3+p_{a}\right)\right)+0.5\right] \cdot k v_{\max }+k v_{\min }$,

on this parameter. Here, $d$ denotes the ocean depth (in $\mathrm{m}$ ) and the factor 0.3 was chosen as a best-guess to set the steepness of the transition.

$k v_{\max }=R_{C} \cdot p_{\min } \cdot D_{P I}$

and

$k v_{\text {min }}=R_{C} \cdot\left(1-p_{\text {min }}\right) \cdot D_{P I}$

15 are used to calculate the maximum and the minimum of the diffusion profiles in relation to the standard value for PI conditions $\left(D_{P I}=2.3 \cdot 10^{-3} \mathrm{~m}^{2} \mathrm{~s}^{-1}\right.$ ). Here, $p_{\min }$ represents the relative minimum of the diffusion, which is set to 0.03 , and $R_{C}$ determines the change of diffusivity above the transition. However, the minimum of the vertical diffusion by depth is determined by the low latitude ocean value (Shaffer et al. 2008)

$D_{p, \min }=2 \cdot 10^{-5} \cdot\left[1+5.5 \cdot\left(1-\exp \left(\frac{d}{40}\right)\right)\right]$

and imposed by computing $D_{p, t o t}=\max \left(D_{p}, D_{p, \min }\right)$. We used $R_{C}=1.0$ to keep the parameter at standard PI conditions in the shallow ocean for simplicity. The function describes a sharp reduction of the high latitude ocean vertical exchange at an ocean depth depending on $p_{a}$ (see below).

This approach isolates deep and intermediate waters in the model high latitude ocean from upper waters and thereby from the atmosphere. This leads to carbon enrichment and isotopic depletion of these deep and intermediate waters. As a consequence of this reduction in ocean vertical exchange, there is a $20 \mathrm{ppm}$ drawdown of $p \mathrm{CO}_{2}$ in the PI atmosphere and a $0.5^{\circ} \mathrm{C}$ reduction in global mean temperature. Furthermore, atmospheric $\delta^{13} \mathrm{C}$ increases by around $0.1 \%$ and $\Delta^{14} \mathrm{C}$ by around $40 \%$. For our efforts to generate an LGM climate state, which constrains all the mentioned variables to proxy data records concurrently, we used the parameter $p_{a}$ to vary the transition depth and thereby the oceanic volume of isolated deep water. This yielded $p_{a}=5$ for our representation of LGM climate and a vertical exchange transition at around $1800 \mathrm{~m}$ depth. Fig. S4 shows this vertical exchange profile as a function of ocean depth. 


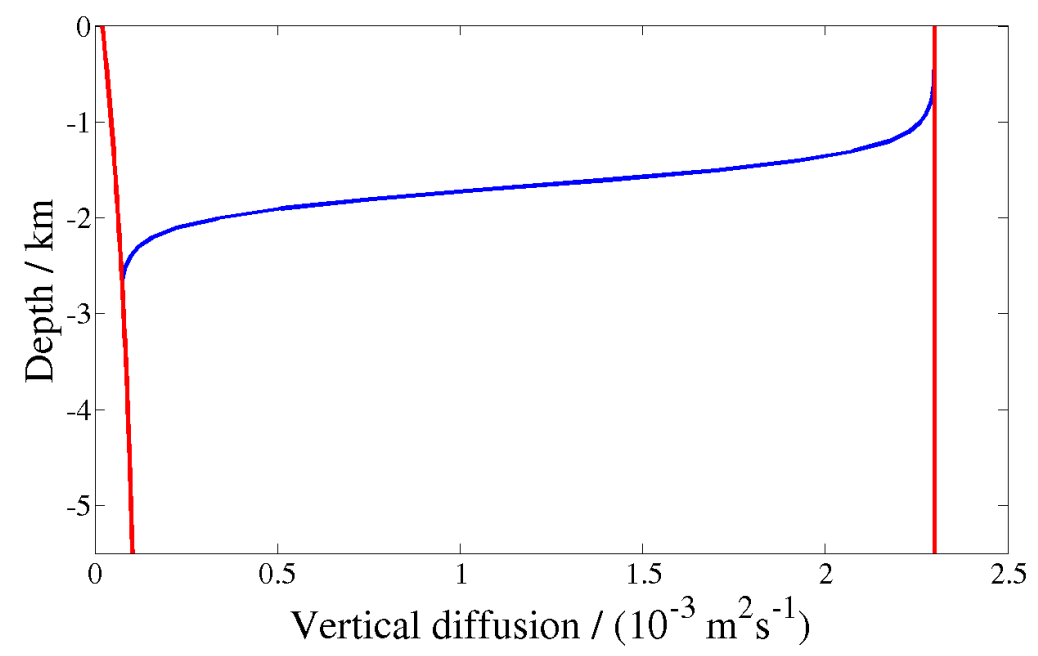

Figure S4. Depth profile of the vertical diffusivity in the high latitude model ocean for generating isolated intermediate and deep waters (blue line, bounded by red lines). The left red line denotes the background vertical mixing from the low latitude model ocean, which serves as a lower boundary and the right red line is the standard PI diffusion and describes the upper boundary for the LGM profile.

\section{S4.2 Resumption of deep ocean mixing}

In order to simulate the resumption of deep ocean mixing during the MI, we impose a steady deepening of the transition depth of the imposed vertical diffusion profile. Starting at year $17.5 \mathrm{kaBP}$ we modify $p_{a}$ in Eq. S4 by

$p_{a}=5+\frac{n}{100} \cdot 0.5$

5 where $\mathrm{n}$ denotes the time step after the start of the resumption. This steadily decreases the transition depth of the vertical diffusion ocean profile over time. Effectively, it leads to the resumption of the high latitude ocean to PI mixing within around $3 \mathrm{ka}$. In other words, this simulates time-dependent upwelling of the deep ocean waters that had been isolated through the imposed vertical mixing profile. Thus, it approximates the sudden event of deep ocean mixing during the MI, that has been hypothesised in a number of studies (e.g. Burke and Robinson, 2012). 


\section{S5 Additional information on model LGM and transition}

The long wave radiative forcing (RF) in the model follows the approximation $R F=A-B \cdot T_{\text {glob }}$ by Budyko (1969), where $T_{\text {glob }}$ denotes the global mean atmosphere temperature (in ${ }^{\circ} \mathrm{C}$ ) and $\mathrm{A}$ and $\mathrm{B}$ are parameters adjusted to achieve desired global mean temperature and climate sensitivity. In order to generate a climate sensitivity of $2.5^{\circ} \mathrm{C}$ for a doubling of atmospheric $\mathrm{CO}_{2}$ concentration (as proposed by Schmittner et al. 2011, for LGM simulations) and to achieve a PI global mean temperature of $15^{\circ} \mathrm{C}$, we choice a value for the longwave radiation temperature sensitivity, B, of $2.21 \mathrm{Wm}^{-2} \mathrm{~K}^{-1}$ and a value for the mean incoming solar radiation at $0^{\circ} \mathrm{C}$, Ao, to be $207.16 \mathrm{Wm}^{-2}$. In the above radiative forcing relation, $A=A_{o}-A_{t}$, whereby $A_{t}$ is the sum of the radiative effects of the deviations of carbon dioxide, methane and nitrous oxide from PI levels. Data reconstructions presented by Schilt et al. (2010) show atmospheric partial pressures of around $p \mathrm{CH}_{4}=380 \mathrm{ppm}$ and $p \mathrm{~N}_{2} \mathrm{O}=200 \mathrm{ppm}$ during the LGM. For the radiation calculations, we adopt these values and prescribe the time series in the transient simulations.

One of the features of the DCESS model is that it is an open system model that considers input from weathering and volcanism and outputs from burial. There is no clear consensus with regard to weathering changes since cooler LGM temperatures may favour less weathering while lower sea level and exposed shelves together with the action of the ice sheets may favour more weathering (e.g. Vance et al. 2009). Furthermore, there is evidence that volcanism may have been affected by lowering sea level and ice sheet loading (Kutterolf et al. 2012). Given this state of affairs and for simplicity, we have chosen to maintain weathering and volcanism constant at the values found for the PI calibration of (Shaffer et al., 2008).

We implemented the transition functions for the ocean phosphate and salinity in the following manner: First, we associate a sea level of $-130 \mathrm{~m}$ below present day values (as during the LGM) to a phosphate concentration scaled by $f_{P}=1.035$. The temporal change of the sea level across the last glacial termination then linearly determines the phosphate concentrations so that $f_{P}=1.0$ is reached, when the sea level is at present day values $(0 \mathrm{~m})$. Analogously, the ocean salinity is prescribed with a value of $35.9 \mathrm{psu}$ for LGM sea level $(-130 \mathrm{~m}$ ) and $34.7 \mathrm{psu}$ for present day (see Adkins et al. 2002).

An overview of all model parameters that were modified additionally to the ocean vertical diffusion is provided in Tab. S1. 


\begin{tabular}{|l|c|c|}
\hline Adjusted parameters & PI & LGM \\
\hline High latitude efficiency factor & 0.36 & 0.5 \\
Phosphate concentration factor & 1 & 1.035 \\
Ocean mean salinity & 34.7 & 35.9 \\
Dust radiative forcing & $0 \mathrm{Wm}^{-2}$ & $-1 \mathrm{Wm}^{-2}$ \\
${ }^{14} \mathrm{C}$ production rate & $1.6 \mathrm{atoms} \cdot \mathrm{cm}^{-1} \mathrm{~s}^{-1}$ & $2.1 \mathrm{atoms} \cdot \mathrm{cm}^{-1} \mathrm{~s}^{-1}$ \\
$p \mathrm{~N}_{2} \mathrm{O}$ for radiation & $270 \mathrm{ppm}$ & $200 \mathrm{ppm}$ \\
$p \mathrm{CH}_{4}$ for radiation & $700 \mathrm{ppm}$ & $380 \mathrm{ppm}$ \\
Snow- / Iceline & $\sim 55^{\circ}$ & $47^{\circ}$ \\
\hline
\end{tabular}

Table S1. Parameter values used to generate the DCESS model LGM climate state.

\section{S6 Model LGM ocean profiles}

The ocean profiles for LGM conditions of various variables for the high and the low-mid latitude sector are presented in Fig. S5 For reference, also observed present day low-mid latitude ocean profiles (Shaffer et al., 2008) are included in the figures. The present day calibrated DCESS model ocean profiles can be found in Shaffer et al. (2008).

A prominent feature in these vertical ocean profiles is generated through the transition of the vertical diffusivity to very low values below around $1800 \mathrm{~m}$ depth. Below the transition, the ocean shows high DIC concentrations and strongly depleted ${ }^{13} \mathrm{C}$ isotope ratios (see Curry et al., 1998; Mackensen et al., 2001; Hesse et al., 2011). For reference, we provide all LGM oceanic sediment $\delta^{13} \mathrm{C}$ measurements south of $46^{\circ} \mathrm{S}$ (Peterson et al. 2014, and citations therein) in Fig. S5 d. These data show quite good agreement with the model simulations considering the sparse measurements and the coarse model resolution. The high latitude ocean below the vertical diffusion transition also shows low oxygen concentrations with minima of $0.05 \mathrm{~mol} \mathrm{~m}^{-3}$ in the deep ocean. This indicates that there is no widespread ocean anoxia in accordance with proxy data (Jaccard et al., 2014). Even though the isolated deep ocean waters are strongly ${ }^{14} \mathrm{C}$-depleted compared to the upper ocean at LGM model conditions, deep ocean $\Delta^{14} \mathrm{C}$ values are still around $150 \%$ higher than at PI conditions. However, since atmospheric $\Delta^{14} \mathrm{C}$ has decreased by more than $400 \%$ from LGM to PI conditions, the difference between atmospheric and oceanic $\Delta^{14} \mathrm{C}$ is much higher during the LGM. $\max \left(\Delta \Delta^{14} \mathrm{C}\right.$ ) (the maximum of $\Delta^{14} \mathrm{C}$ differences between atmosphere and ocean) is around $-480 \%$ during the LGM and also agrees well with observations (Burke and Robinson, 2012). Tab. S2 provides an overview of the result of key model variables of atmosphere and ocean for PI and LGM conditions as well as the proxy data LGM values for comparison. 

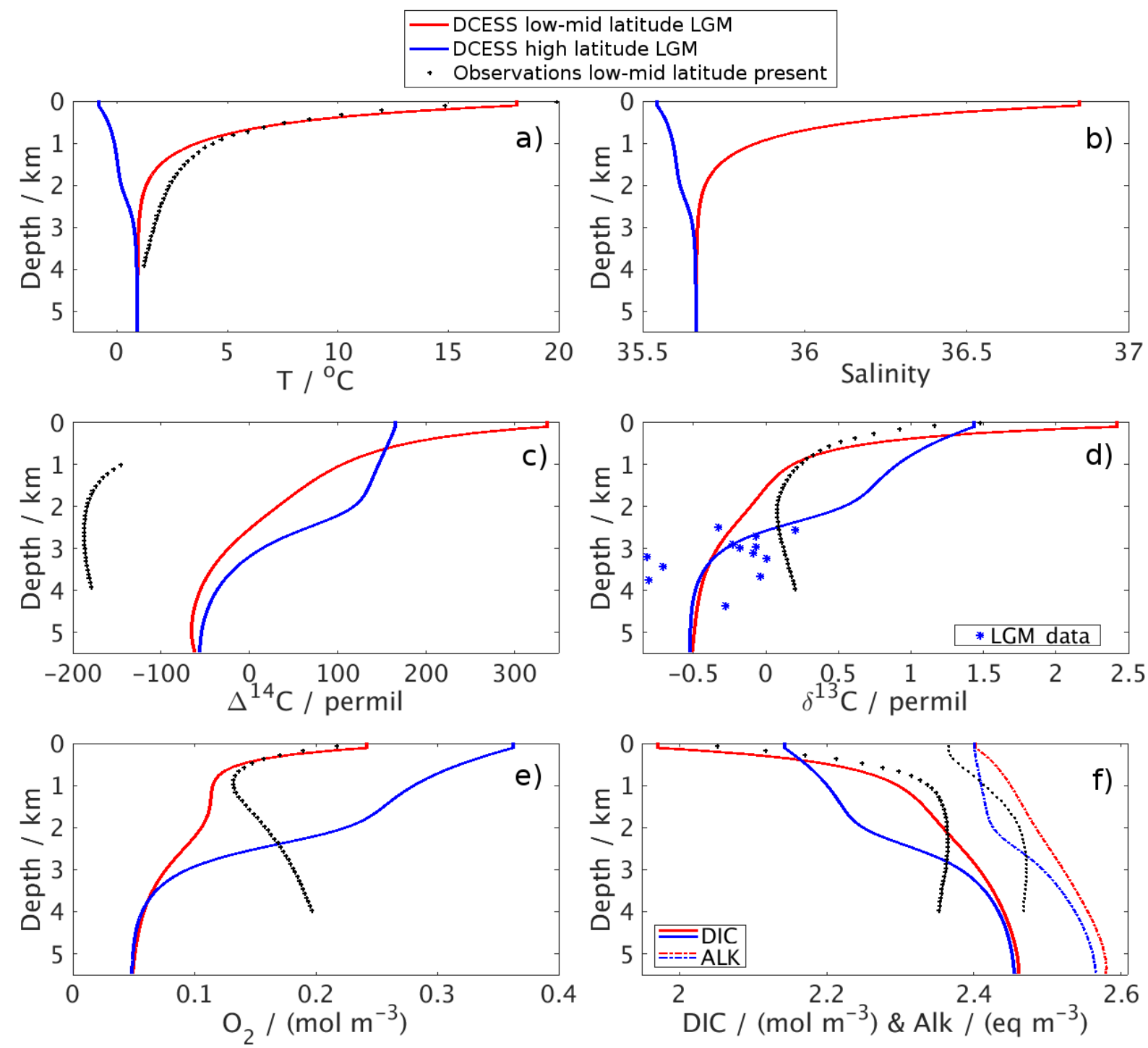

Figure S5. Profiles of the DCESS model ocean at LGM conditions after $80 \mathrm{ka}$ of integration. Blue: high latitude model ocean profiles; red: low-mid latitude ocean profiles; black: observed present day low-mid latitude ocean profiles (Shaffer et al., 2008). 


\begin{tabular}{|c|c|c|c|c|}
\hline variable & Model PI & Model LGM & Proxy data LGM & Reference \\
\hline $\mathrm{T}_{a t m}$ & $14.96^{\circ} \mathrm{C}$ & $11.70^{\circ} \mathrm{C}$ & $11.5-11.8^{\circ} \mathrm{C}$ & Shakun et al. (2012) \\
\hline$p \mathrm{CO}_{2}$ & $278.2 \mathrm{ppm}$ & $187.9 \mathrm{ppm}$ & $186-198 \mathrm{ppm}$ & Lüthi et al. (2008) \\
\hline$\delta^{13} \mathrm{C}_{a t m}$ & $-6.06 \%$ & $-6.41 \%$ & $-(6.38-6.46) \%$ & Schmitt et al. (2012) \\
\hline$\Delta^{14} \mathrm{C}_{a t m}$ & $4.3 \%$ & $414.5 \%$ & $400-570 \%$ & Reimer et al. 2013) \\
\hline $\min \left(\delta^{13} \mathrm{C}_{\text {oce }}\right)$ & $0.2 \%$ & $-0.5 \%$ & $-(1.1-0.3) \% \circ$ & Peterson et al. (2014) \\
\hline $\max \left(\Delta \Delta^{14} \mathrm{C}_{\text {oce }}\right)$ & $5 \%$ & $-480 \%$ & $\sim-500 \%$ & Burke and Robinson (2012) \\
\hline $\min \left(\mathrm{O}_{2, \text { oce }}\right)$ & $0.12 \mathrm{~mol} \cdot \mathrm{m}^{-3}$ & $0.05 \mathrm{~mol} \cdot \mathrm{m}^{-3}$ & low but not anoxic & Jaccard et al. (2014) \\
\hline
\end{tabular}

Table S2. Atmospheric and oceanic model variables for PI and LGM climate conditions and LGM proxy data for comparison. The range of the proxy data values express their variability between 18 and $25 \mathrm{kaBP}$.

\section{S7 Background information on the Mystery Interval}

One leading hypothesis for explaining the initial step of the last glacial termination ("Mystery Interval" (MI), from 17.5 to 14.5 kaBP; Broecker and Barker. 2007) is enhanced upward exchange of and subsequent outgassing from SO deep water (Francois et al., 1997; Sigman and Boyle, 2000). This water had been isolated from surface layers and thereby had been arecumulating carbon from remineralisation of organic matter during the previous glacial time (Broecker and Barker. 2007). Such enhanced transport could result from a number of processes. These include a strengthening and/or poleward shift of the Southern Hemisphere west wind belt that would enhance deep SO upwelling (Toggweiler and Russel, 2008, Anderson et al. 2009, d'Orgeville et al. 2010) and changes in ocean stratification through brine-induced effects on glacial-interglacial time scales that would enhance deep SO convection and mixing (Bouttes et al., 2010, 2011, Mariotti et al., 2013, 2016). In addition to such changes, a number of other processes, such as variations in iron fertilisation of the SO, ocean volume changes, as well as carbon storage in the terrestrial biosphere (e.g. Kohfeld and Ridgwell, 2009) and in permafrost (e.g. Zech, 2012; Köhler et al. 2014; Crichton et al., 2016), have to be considered.

Recently, consistent records of carbon isotopes from ice cores have become available for use in constraining processes that control the global carbon cycle. Carbon isotope ratios are sensitive to variations in carbon exchange between the atmosphere, the terrestrial biosphere and the ocean reservoirs, but also to other effects on geological time scales such as changes in oceanic biogeochemical conditions. Therefore, analyses of the variations of isotope ratios can provide deeper insights into the mechanisms that are responsible for the $p \mathrm{CO}_{2}$ and hence temperature increase. For example Reimer et al. (2013) and Schmitt et al. (2012) presented time series of reconstructions of the two carbon isotope ratios $\Delta^{14} \mathrm{C}$ and $\delta^{13} \mathrm{C}$ in the atmosphere during the past $25 \mathrm{ka}$. Both $\Delta^{14} \mathrm{C}$ and $\delta^{13} \mathrm{C}$ show a relatively sharp drop during the MI. While $\Delta^{14} \mathrm{C}$ continues to decrease after that until present day, $\delta^{13} \mathrm{C}$ rises again during the Holocene after first practically stagnating for around $4 \mathrm{ka}$. Schmitt et al. (2012) suggest that $\delta^{13} \mathrm{C}$ is significantly influenced by ocean temperature changes only during the stagnating phase. The sharp drop 
can be related to the outgassing of isolated deep waters and the regrowth of the terrestrial biosphere can account for the increase during the Holocene. $\Delta^{14} \mathrm{C}$ is largely affected by its cosmogenic production rate (see e.g. Lal and Peters, 1967), but estimates of ${ }^{14} \mathrm{C}$ production rates indicate that air-sea carbon exchange has to be considered to explain the $\Delta^{14} \mathrm{C}$ drop during the MI (Laj et al., 2004, Muscheler et al. 2004, 2005, Hain et al. 2014). Burke and Robinson (2012) used deep sea coral

5 data to reconstruct concentrations of this radioactive tracer (Half-life: $T_{1 / 2}\left({ }^{14} \mathrm{C}\right) \approx 5730$ a) in different oceanic water masses. Isotopically strongly depleted water masses can be found in the deep and intermediate SO (Sikes et al., 2000, Skinner et al. 2010, Thornalley et al. 2011). Due to the slow radioactive decay of ${ }^{14} \mathrm{C}$, isolation of these water masses from surface waters can account for this isotopic depletion during the last glacial. At the onset of the last glacial termination, $\Delta{ }^{14} \mathrm{C}$ in deep ocean waters rapidly increased, which indicates a sudden event of deep ocean mixing, transporting isotopically depleted waters from the deep to the upper ocean regions and hence also supporting the hypothesis of enhanced SO vertical transport (Burke and Robinson, 2012). Thereafter, deep ocean $\Delta^{14} \mathrm{C}$ does not change significantly until the early Holocene. This indicates that the increase of atmospheric $\mathrm{CO}_{2}$ in the latter part of the deglaciation is not primarily driven from the deep ocean.

Nevertheless, several studies call into question enhanced oceanic vertical transport as the conclusive reason for atmospheric $\mathrm{CO}_{2}$ and temperature variations during the MI. Due to limitations of the volume of an abundant isolated ocean reservoir, Broecker and Barker (2007) doubt that the magnitude of such an event could account for the observed atmospheric $\mathrm{CO}_{2}$ changes. Mainly because of the lack of low $\Delta^{14} \mathrm{C}$ in their measurements De Pol-Holz et al. (2010), Broecker and Clark (2010) and Cléroux et al. (2011) question the existence of such strongly depleted ocean reservoirs. Moreover, modelling work by Hain et al.(2011) report shortcomings of the isolated reservoir hypothesis. Amongst other reasons the study claims that the isolation causes wide-spread anoxia in the deep ocean (which was not reported by proxy data, see e.g., Jaccard et al., 2014) and that the carbon signal would rapidly be dissipated and diluted in the rest of the ocean. Other studies question the SO to be the origin of the event. Okazaki et al. (2010) argue that North Pacific water masses could help to explain the release of old carbon during the last glacial termination and Kwon et al. (2012) point out the possible influence of deep North Atlantic water masses for this process. In an Earth System Model study, Huiskamp and Meissner (2012) find old water masses in different oceanic reservoirs in response to variations of the mechanisms for deep water formation. 


\section{S8 Model Mystery Interval changes}

To assess the impacts of the individual transition functions on atmospheric $\mathrm{T}_{g l o b}, p \mathrm{CO}_{2}, \delta^{13} \mathrm{C}$ and $\Delta^{14} \mathrm{C}$ changes, four transient simulations have been conducted in the following manner: First, only the prescription of the two minor greenhouse gases methane and nitrous oxide, as well as the variations in ice sheet expansion are activated (simulation: Min_RF, Minor radiative

5 forcing). In the second simulation, the ocean vertical mixing is additionally restored as described above (Add_vdiff, additional resumption of ocean vertical diffusion). In the third simulation, variations in atmospheric dust concentrations are simulated on top of the other two effects through their impact on the radiative forcing and the iron limitation factor (Add_dust, additional application of the dust transition functions). In the final simulation with all changes, the ocean phosphate inventory and the ocean salinity transition functions are applied as well (REF, use of all transition functions). The four panels in Fig. S6 show the four atmospheric variables and data-based reconstructions for these four simulations between 20 and $10 \mathrm{kaBP}$, including the MI.

As expected, changes in only methane, nitrous oxide and the ice sheet extent (Min_RF) have almost no influence on atmospheric $p \mathrm{CO}_{2}$, and the temperature increase is also modest. The growth of the terrestrial vegetation through the prescribed ice sheet retreat even leads to a decrease in $p \mathrm{CO}_{2}$ until about $16 \mathrm{kaBP}$. Up to this time, the latitude of the ice sheets extends farther equatorward than the snowline (see Fig. S33, note that in the Min_RF simulation the two lines cross earlier because of the slower increase of the snowline latitude). $\delta^{13} \mathrm{C}$ and $\Delta^{14} \mathrm{C}$ also show only minor changes, which are due to temperature and vegetation changes for $\delta^{13} \mathrm{C}$ and mainly production rate-driven for $\Delta^{14} \mathrm{C}$. The additional resumption of the ocean high latitude vertical diffusion (Add_vdiff) generates a $p \mathrm{CO}_{2}$ change of around $18 \mathrm{ppm}$ during the MI. Furthermore, $\delta^{13} \mathrm{C}$ and $\Delta^{14} \mathrm{C}$ drop within these $3 \mathrm{ka}$ by an additional $0.14 \%$ and $60 \%$, respectively, due to the outgassing of the isotopically depleted deep waters.

20 The dust-dependent iron limitation factor, as well as radiative forcing changes that are switched on in the third simulation (Add_Dust) again enhance the changes of all four quantities during the MI. However, the changes of all four quantities only reach about half of the proxy data levels. The additions of the ocean phosphate and ocean salinity transition functions (REF) do not resolve this apparent shortcoming of the model simulation. These modulations only lead to very small changes. 

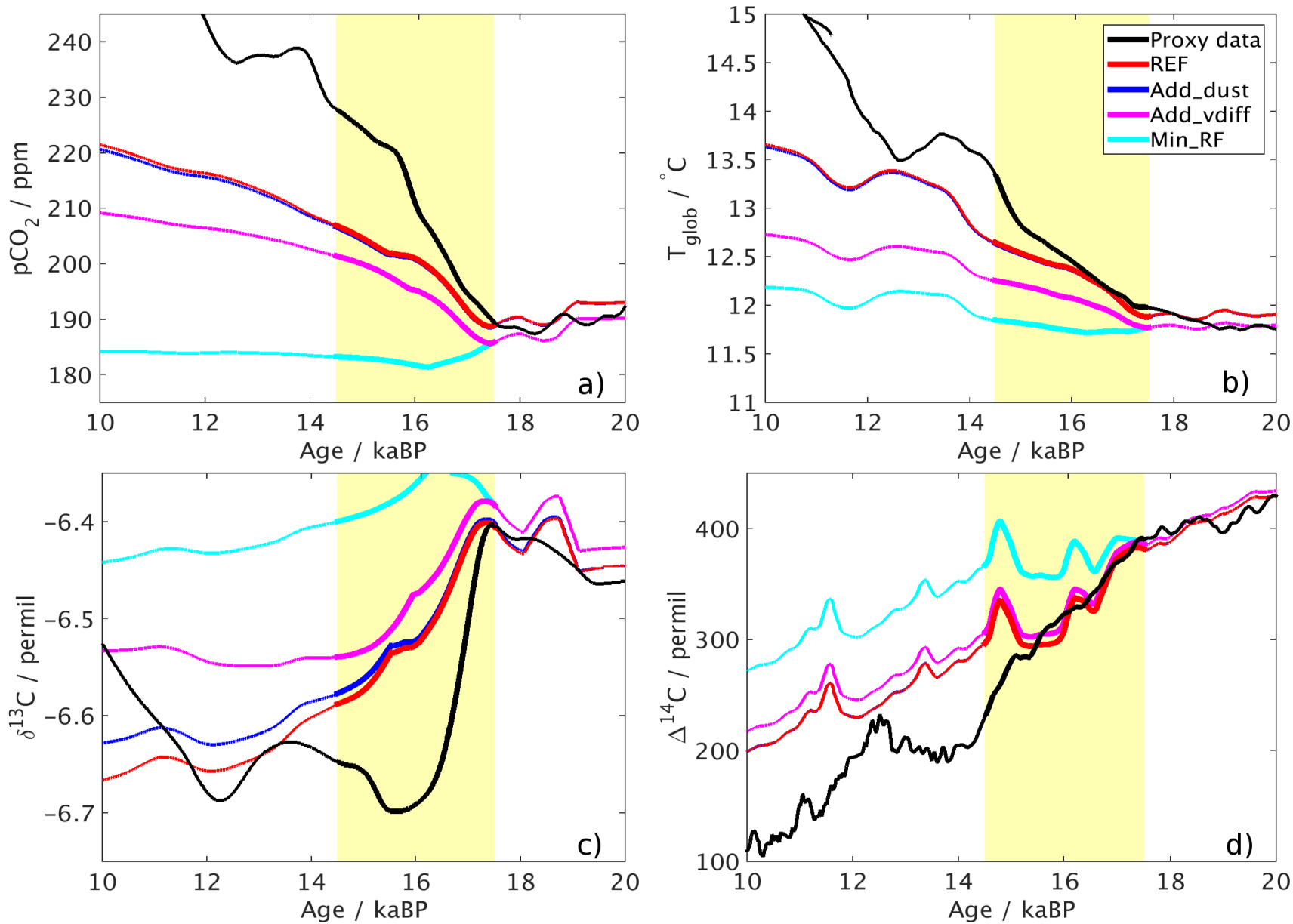

Figure S6. Atmospheric values (a: $p \mathrm{CO}_{2}$, b: global mean temperature, c: $\delta^{13} \mathrm{C}$ and d: $\Delta^{14} \mathrm{C}$ ) for transient DCESS simulations from 20 to $10 \mathrm{kaBP}$ and data-based reconstructions. Black: Data-based reconstructions; $p \mathrm{CO}_{2}$ by Lüthi et al. (2008), temperatures by Shakun et al. (2012), $\delta^{13} \mathrm{C}$ by Schmitt et al. (2012) and $\Delta^{14} \mathrm{C}$ by Reimer et al. (2013); cyan: DCESS simulation only with prescribed ice sheet extent and minor greenhouse gas forcing (Min_RF); magenta: as cyan, additionally with restored high latitude vertical exchange (Add_vdiff); blue: as magenta, additionally with prescribed temperature-dependent dust concentration (for radiative forcing and iron-limitation) (Add_dust); red: as blue, additionally with sea level-dependent phosphate and salinity variation (REF). The yellow shading indicates the MI from 17.5 to $14.5 \mathrm{kaBP}$. Note that at many stages the blue Add_dust line is covered by the red REF line. 


\section{S9 Details on ${ }^{14} \mathrm{C}$ production rate determination}

The ${ }^{14} \mathrm{C}$ production rate production rate is determined by the strength of the Earth's magnetic field, which shields the atmo\sphere from high energy cosmic particles, and the solar modulation of the incidence of high energy cosmic particles (Lal and Peters, 1967, Hain et al. 2014). Here, we present the three cosmogenic ${ }^{14} \mathrm{C}$ production rate time series from the studies by

5 Muscheler et al. (2004); Laj et al. (2004) and Hain et al. (2014) that were applied in our experiments. Based on the GLobal PaleoIntensity Stack (GLOPIS-75), Laj et al. (2004) determined the ${ }^{14} \mathrm{C}$ production rate as a function of past changes in geomagnetic field intensity using the conversion of Masarik and Beer (1999). Hain et al. (2014) have further processed these data with a Monte-Carlo simulation with 1000 members of randomised magnetic field strength records within the GLOPIS-75 uncertainty envelope and a more recent ${ }^{14} \mathrm{C}$ production rate model by Kovaltsov et al. (2012) with updated cosmic ray spectra. Muscheler et al. (2004) have used a different approach to infer the ${ }^{14} \mathrm{C}$ production rate across the last $25 \mathrm{ka}$ based on high resolution ${ }^{10} \mathrm{Be}$ measurements from GRIP and GISP2 ice cores. Assuming that the atmospheric processes of ${ }^{10} \mathrm{Be}$ (attachment on aerosols and deposition after a mean residence time of $1-2$ years in the atmosphere) are understood, the ${ }^{14} \mathrm{C}$ production rate can be estimated rather directly, because ${ }^{10} \mathrm{Be}$ and ${ }^{14} \mathrm{C}$ are produced by similar processes in the atmosphere (Lal and Peters 1967, Masarik and Beer, 1999). This reconstruction takes into account all probable causes of production rate variations, such as variations in geomagnetic field, solar activity and/or in the interstellar galactic cosmic rays flux (Muscheler et al. 2004).

In their studies, Muscheler et al. (2004) as well as Laj et al. (2004) only provide normalised (around 1) values for the ${ }^{14} \mathrm{C}$ production rate, because the determination of the absolute values is very uncertain. Only the more recent study by Hain et al. (2014) provides these absolute values (in atoms $/ \mathrm{cm}^{-2} s$ ). For this reason, we scaled the two other data sets by factors that yield ${ }^{14} \mathrm{C}$ production rates throughout the last $25 \mathrm{kaBP}$ that are close to the data by Hain et al. (2014) and moreover, lead to atmospheric $\Delta^{14} \mathrm{C}$ results close to the data based reconstructions at the beginning of the MI in the DCESS simulations. An evaluation of good fits for these scaling factors yielded $1.5 \cdot 10^{4}$ atoms $\cdot \mathrm{cm}^{2} \mathrm{~s}^{-1}$ for the data by Muscheler et al. (2004) and $1.35 \cdot 10^{4}$ atoms $\cdot \mathrm{cm}^{2} \mathrm{~s}^{-1}$ for the data by Laj et al. (2004). For the box diffusion model-calculated ${ }^{14} \mathrm{C}$ production rate (Muscheler et al. 2005, see Fig. 6), the most likely absolute values are generated by multiplication with $1.8 \cdot 10^{4}$ atoms $\cdot \mathrm{cm}^{2} \mathrm{~s}^{-1}$ (R. Muscheler, personal communication, 2015). In Fig. S7, the three ${ }^{14} \mathrm{C}$ production rate time series are shown.

Generally, the three individual ${ }^{14} \mathrm{C}$ production rates show similar patterns across the last $25 \mathrm{kaBP}$ but with a couple of differences. The data by Hain et al. (2014) and by Laj et al. (2004) are derived using the same approach and the general features and local extrema therefore show the same timing, although the time series by Hain et al. (2014) seems somewhat smoother with a smaller general trend. The data by Muscheler et al. (2004) shows far stronger and more high-frequent fluctuations than the other two data sets, the general trend, however, is similar. Only between 20 and $23 \mathrm{kaBP}$ do the time series of the different approaches show an opposing behaviour. While the data set by Muscheler et al. (2004) shows a minimum during that period, the other two time series possess maxima here. Between the beginning and the end of the MI, all data sets are exhibit similar structure. However, over these $3 \mathrm{ka}$, a reduction of $0.11 \mathrm{atmos} / \mathrm{cm}^{2} \mathrm{~s}$ can be seen in the data by Hain et al. (2014), p.19 atmos $/ \mathrm{cm}^{2} s$ in the data by Laj et al. (2004) and even a slight increase of $0.02 \mathrm{atmos} / \mathrm{cm}^{2} s$ in the data by Muscheler et al. (2004). 


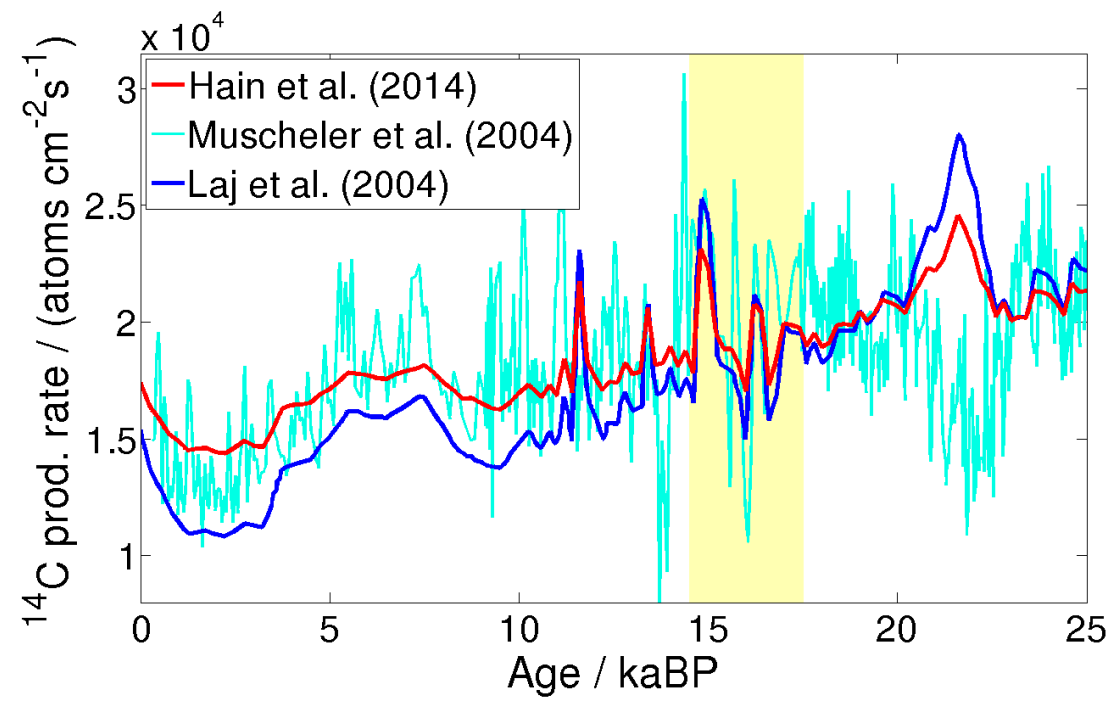

Figure S7. Three estimates of the ${ }^{14} \mathrm{C}$ production rate. Muscheler et al. (2004) (cyan) scaled by 1.5, Laj et al. (2004) (blue), scaled by 1.35 and Hain et al. (2014) (red). The MI is indicated by yellow shading.

\section{S10 Model ${ }^{14} \mathrm{C}$ production rate}

In this section, we calculate the model ${ }^{14} \mathrm{C}$ production rate. Defined as the rate that would be required to yield proxy data-based $\Delta^{14} C$ estimates for the model simulation. For example Muscheler et al. (2005) have shown that this can help to better assess production rate determination. This means that we set the ${ }^{14} \mathrm{C}$ production rate to 0 and prescribe atmospheric $\Delta{ }^{14} \mathrm{C}$ to the data based reconstructions (from Reimer et al., 2013). The difference between the calculated model $\Delta^{14} \mathrm{C}$ and the data time series then yields the ${ }^{14} \mathrm{C}$ production rate that would be needed to generate the reconstructed $\Delta^{14} \mathrm{C}$ values in the model simulation. For comparison with this DCESS calculated ${ }^{14} \mathrm{C}$ production rate, Fig. $\mathrm{S} 8$ shows the uncertainty ranges of the data from the studies by Muscheler et al. (2004) and by Hain et al. (2014) and the ${ }^{14} \mathrm{C}$ production rate calculated with a box diffusion model by Muscheler et al. (2005). Due to the fact that the data of Laj et al. (2004) are apparently supersided through their revision by Hain et al. (2014) (see previous section), we did not consider the Laj et al. (2004) time series for this part of our study. We present this computation for one simulation with all changes as presented in the manuscript (the REF simulation) and for one simulation with prescribed $p \mathrm{CO}_{2}$ to provide an estimate for the influence of the model underestimated $p \mathrm{CO}_{2}$ on the calculation of $\Delta^{14} \mathrm{C}$.

Even though model-calculated and prescribed $p \mathrm{CO}_{2}$ differ by up to $20 \mathrm{ppm}$ during some periods of the simulation, the ${ }^{14} \mathrm{C}$ production rate results of the two different model simulations are practically the same. This shows that changes of atmospheric ${ }^{12} \mathrm{C}$ only weakly influence $\Delta^{14} \mathrm{C}$ compared to variations of ${ }^{14} \mathrm{C}$. In the first half of the MI, the DCESS production rate still agrees well with the data sets, but at around $15 \mathrm{kaBP}$, the DCESS time series drops while both data sets show an increase. Hence, the calculated production rate lies below both uncertainty ranges at that period, where also a large offset between 


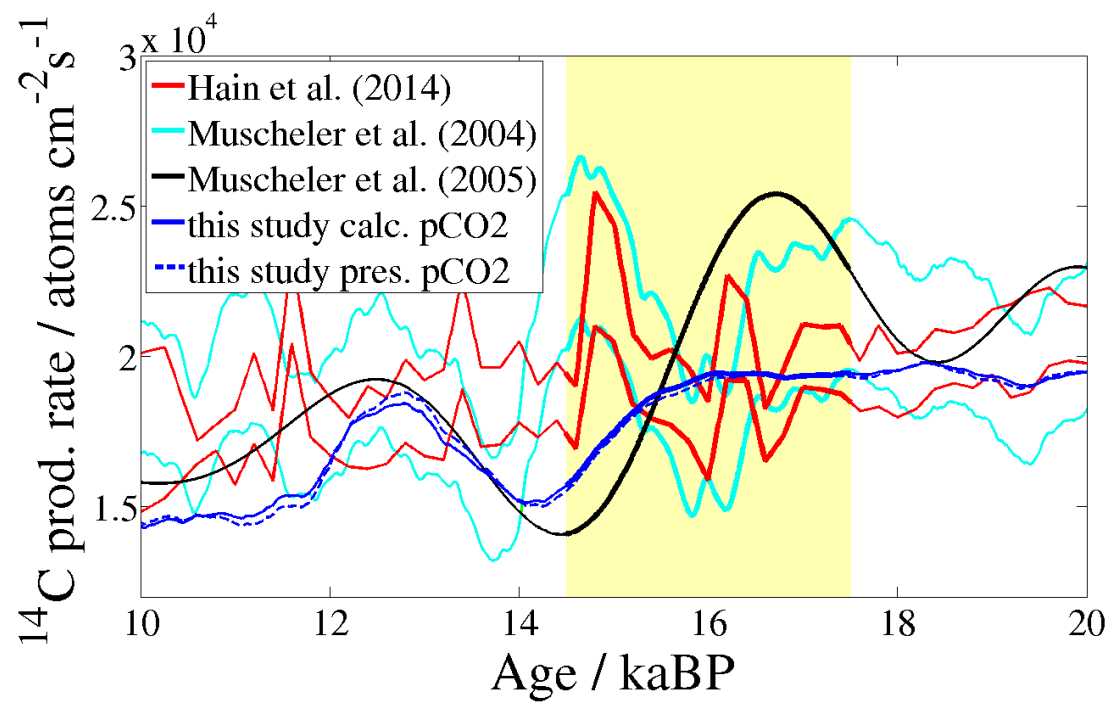

Figure S8. Uncertainty ranges of the ${ }^{14} \mathrm{C}$ production rate time series of the studies by Hain et al. (2014) (red) and by Muscheler et al. (2004) (cyan, processed with a 1000 a running mean), calculated ${ }^{14} \mathrm{C}$ production rate from Muscheler et al. (2005) (black) and DCESS ${ }^{14} \mathrm{C}$ production rate calculated to meet the $\Delta^{14} \mathrm{C}$ data by (Reimer et al. 2013) (blue solid: as REF simulation; blue dashed: with prescribed $p \mathrm{CO}_{2}$ from Lüthi et al. (2008), both processed with a 100 a running mean). The MI is indicated by yellow shading.

pobserved and modelled $\Delta^{14} \mathrm{C}$ can be seen in Fig. $\mathrm{S} 8$. The box diffusion model calculated ${ }^{14} \mathrm{C}$ production rate by Muscheler et al. (2005) also shows a strong decrease during this period where the observational data rises. After this peak, the observations decrease again and agree well with the DCESS calculations thereafter, particularly the time series by Muscheler et al. (2004). Across the Holocene, the DCESS calculated ${ }^{14} \mathrm{C}$ production rate is rather at the low end of the uncertainty ranges of the proxy 5 data sets.

The model-calculated ${ }^{14} \mathrm{C}$ production rate lies within the proxy data-based uncertainty limits during most of the simulation but shows large deviations at the end of the MI. This discrepancy can also be observed in the box diffusion model-calculated time series by Muscheler et al. (2005) (which assumes a constant carbon cycle). Hence, this approach can not answer the question if it is the lack of an important process in the model, which could possibly also account for the remaining increase of atmospheric $p \mathrm{CO}_{2}$, or errors in the production rate data sets that lead to these deviations. 


\section{S11 Isotope ratio definitions}

Isotope ratios are determined by

$\delta^{13} C=\left(\frac{\frac{{ }^{13} C}{12 C}}{R_{p d b}^{13}}-1\right) \cdot 1000$

with the 'Pee-Dee Belemnite' standard $R_{p d b}^{13}=0.0112372$ (Zhang et al. 1990 ) for the ${ }^{13} \mathrm{C} /{ }^{12} \mathrm{C}$ ratio and by

${ }_{5} \Delta^{14} C=\left[\frac{\frac{{ }^{14} C}{12 C}}{R_{\text {oas }}^{14}}\left(\frac{R_{p d b}^{13} \cdot 0.975}{\frac{13 C}{{ }^{12} C}}\right)^{2}-1\right] \cdot 1000$

with the 'Oxalic Acid Standard' $R_{\text {oas }}^{14}=1.176 \cdot 10^{-12}$ for the ${ }^{14} \mathrm{C} /{ }^{12} \mathrm{C}$ ratio (Karlen et al., 1964). 


\section{References}

Adkins, J. F., McIntyre, K., and Schrag, D. P.: The Salinity, Temperature, and $\delta^{18}$ O of the Glacial Deep Ocean, Science, 298, 1769-1773, doi $10.1038 / 35038000,2002$.

Anderson, R. F., Ali, S., Bradtmiller, L., Nielsen, S. H. H., Fleisher, M. Q., Anderson, B. E., and Buckle, L. H.: Wind-Driven Upwelling in the Southern Ocean and the Deglacial Rise in Atmospheric $\mathrm{CO}_{2}$, Science, 323, 1443-1448, doi $10.1126 /$ science.1167441 2009.

Bouttes, N., Paillard, D., and Roche, D. M.: Impact of brine-induced stratification on the glacial carbon cycle, Climate of the Past, 6, 681-710, doi $10.5194 /$ cp-6-575-2010 2010.

Bouttes, N., Paillard, D., Roche, D. M., Brovkin, V., and Bopp, L.: Last Glacial Maximum $\mathrm{CO}_{2}$ and $\delta^{13} \mathrm{C}$ successfully reconciled, Geophysical Research Letters, 38, L02 705, doi:10.1029/2010GL044499 2011.

Broecker, W. and Barker, S.: A $190 \%$ drop in atmosphere's $\Delta^{14} \mathrm{C}$ during the "Mystery Interval" (17.5 to 14.5 kyr), Earth and Planetary Science Letters, 256, 90-99, doi 10.1016/j.eps1.2007.01.015.2007.

Broecker, W. and Clark, E.: Search for a glacial-age ${ }^{14}$ C-depleted ocean reservoir, Geophysical Research Letters, 37, L13606, doi $10.1029 / 2010$ GL043969 2010.

Budyko, M. I.: The effect of solar radiation variations on the climate of the Earth, Tellus, 84, 611-619, doi 10.1111/j.21533490.1969.tb00466.x. 1969.

Burke, A. and Robinson, L. F.: The Southern Ocean's Role in Carbon Exchange During the Last Deglaciation, Science, 335, 557-561, doi $10.1126 /$ science.1208163 2012.

Cléroux, C., deMenocal, P., and Guilderson, T.: Deglacial radiocarbon history of tropical Atlantic thermocline waters: absence of $\mathrm{CO}_{2}$ reservoir purging signal, Quaternary Science Review, 30(15-16), 1875-1882, doi 10.1016/j.quascirev.2011.04.015. 2011.

Crichton, K. A., Bouttes, N., Roche, D. M., Chappellaz, J., and Krinner, G.: Permafrost carbon as a missing link to explain $\mathrm{CO}_{2}$ changes during the last deglaciation, Nature, 9, 683-687, doi 10.1038/NGEO2793, 2016.

Curry, W. B., Duplessy, J. C., Labeyrie, L. D., and Shackleton, N. J.: Changes in the distribution of ${ }^{13} \mathrm{C}$ of deep water $\sum \mathrm{CO}_{2}$ bewtween the last glaciation and the Holocene, Paleoceanography, 3, 317-341, doi 10.1029/PA003i003p00317. 1998.

De Pol-Holz, R., Keigwin, L., Southon, J., Hebbeln, D., and Mohtadi, M.: No signature of abyssal carbon in intermediate waters off Chile during deglaciation, Nature Geoscience, 3, 192-195, doi:10.1038/ngeo745, 2010.

d'Orgeville, M., Sijp, W. P., England, M. H., and Meissner, K. J.: On the control of glacial-interglacial atmospheric $\mathrm{CO}_{2}$ variations by the Southern Hemisphere westerlies, Geophysical Research Letters, 37, L21 703, doi 10.1029/2010GL045261 2010.

Francois, R., Altabet, M. A., Yu, E.-F., Sigman, D. M., Bacon, M. P., Frank, M., Bohrmann, G., Bareille, G., and Labeyrie, L. D.: Contribution of Southern Ocean surface-water stratification to low atmospheric $\mathrm{CO}_{2}$ concentrations during the last glacial period, Nature, 389, 929-935, doi: $10.1038 / 40073,1997$.

Hain, M. P., Sigman, D. M., and Haug, D. H.: Shortcomings of the isolated abyssal reservoir model for deglacial radiocarbon changes in the mid-depth Indo-Pacific Ocean, Geophysical Research Letters, 38, L04 604, doi doi:10.1029/2010GL046158 2011.

Hain, M. P., Sigman, D. M., and Haug, G. H.: Distinct roles of the Southern Ocean and North Atlantic in the deglacial atmospheric radiocarbon decline, Earth and Planetary Science Letters, 394, 198-208, doi:10.1016/j.eps1.2014.03.020 2014.

Hesse, T., Butzin, M., Bickert, T., and Lohmann, G.: A model-data comparison of $\delta^{13} \mathrm{C}$ in the glacial Atlantic Ocean, Paleoceanography, 26, PA3220, doi 10.1029/2010PA002085 2011. 
Huiskamp, W. N. and Meissner, K. J.: Oceanic carbon and water masses during the Mystery Interval: A model-data comparison study, Paleoceanography, 27, PA4206, doi 10.1029/2012PA002368 2012.

Jaccard, S. L., Galbraith, E. D., Fröhlicher, T. L., and Gruber, N.: Ocean (de)oxygenation across the last deglaciation: Insights for the future, Oceanography, 27 (1), 26-35, doi 10.5670/oceanog.2014.05, 2014.

5 Jouzel, J., Masson-Delmotte, V., Cattani, O., Dreyfus, G., Falourd, S., Hoffmann, G., Minster, B., Nouet, J., Barnola, J. M., Chappellaz, J., Fischer, H., Gallet, J. C., Johnsen, S., Leuenberger, M., Loulergue, L., Luethi, D., Oerter, H., Parrenin, F., Raisbeck, G., Raynaud, D., Schilt, A., Schwander, J., Selmo, E., Souchez, R., Spahni, R., Stauffer, B., Steffensen, J. P., Stenni, B., Stocker, T. F., Tison, J. L., Werner, M., and Wolff, E. W.: Orbital and Millennial Antarctic Climate Variability over the Past 800,000 Years, Science, 317, 793-796, doi $10.1126 /$ science.1141038, 2007.

10 Karlen, I., Olsson, I. U., Kallburg, P., and Kilici, S.: Absolute determination of the activity of two 14C dating standards, Arkiv Geofysik, 4, 465-471, 1964.

Kohfeld, K. E. and Ridgwell, A.: Glacial-Interglacial Variability in Atmospheric $\mathrm{CO}_{2}$, Geophysical Research Series, 187, 251-286, doi $10.1029 / 2008$ GM000845, 2009.

Köhler, P., Knorr, G., and Bard, E.: Permafrost thawing as a possible source of abrupt carbon release at the onset of the Bølling/Allerød, Nature Communications, 5, 5520, doi $10.1038 /$ ncomms6520 2014.

Kovaltsov, G. A., Mishev, A., and Usoskin, I. G.: A new model of cosmogenic production of radiocarbon ${ }^{14} \mathrm{C}$ in the atmosphere, Earth and Planetary Science Letters, 337, 114-120, doi $10.1016 /$ j.epsl.2012.05.036, 2012.

Kutterolf, S., Jegen, M., Mitrovica, J. X., Kwasnitschka, T., Freundt, A., and Huybers, P. J.: A detection of Milankovitch frequencies in global volcanic activity, Geology, 41, 227-230, doi:10.1130/G33419.1 2012.

20 Kwon, E. Y., Hain, M. P., Sigman, D. M., Galbraith, E. D., Sarmiento, J. L., and Toggweiler, J. R.: North Atlantic ventilation of "southernsourced" deep water in the glacial ocean, Paleoceanography, 27, PA2208, doi:10.1029/2011PA002211, 2012.

Laj, C., Kissel, C., and Beer, J.: High resolution global paleointensity stack since 75 kyr (GLOPIS-75) calibrated to absolute values, in: Geophysical Monograph Series (AGU), 145, 255-265, doi:10.1029/145GM19, 2004.

Lal, D. and Peters, B.: Cosmic rays produced radioactivity on the Earth, Encyclopedia of Physics, Cosmic Rays II, 46, 551-612, doi $10.1007 / 978-3-642-46079-1 \_7,1967$.

Lambert, F., Bigler, M., Steffensen, J. P., Hutterli, M., and Fischer, H.: Centennial mineral dust variability in high-resolution ice core data from Dome C, Antarctica, Climate of the Past, 8, 609-623, doi 10.5194/cp-8-609-2012 2012.

Lambert, F., Kug, J.-S., Park, R. J., Mahowald, N., Winckler, G., Abe-Ouchi, A., O'ishi, R., Takemura, T., and Lee, J.-H.: The role of mineral-dust aerosols in polar temperature amplification, Nature Climate Change, 3, 487-491, doi 10.1038/nclimate1785. 2013.

30 Lambert, F., Tagliabue, A., Shaffer, G., Lamy, F., Winckler, G., Farias, L., Gallardo, L., and De Pol-Holz, R.: Dust fluxes and iron fertilization in Holocene and Last Glacial Maximum climates, Geophysical Research Letters, 42, 6014-6023, doi:10.1002/2015GL064250. 2015.

Lüthi, D., Le Floch, M., Bereiter, B., Blunier, T., Barnola, J. M., Siegenthaler, U., Raynaud, D., Jouzel, J., Fischer, H., Kawamura, K., and Stocker, T. F.: High-resolution carbon dioxide concentration record 650,000-800,000 years before present, Nature, 453, 379-382, doi 10.1038 /nature06949. 2008.

35 Mackensen, A., Rudolph, M., and Kuhn, G.: Late Pleistocene deep-water circulation in the subantarctic eastern Atlantic, Global and Planetary Change, 30, 197-229, doi:10.1016/S0921-8181(01)00102-3, 2001. 
Maher, B. A., Prospero, J. M., Mackie, D., Gaiero, D., Hesse, P., and Balkanski, Y.: Global connections between aeolian dust, climate and ocean biogeochemistry at the present day and at the last glacial maximum, Earth-Science Reviews, 99, 61-97, doi 10.1016/j.earscirev.2009.12.001, 2010.

Mahowald, N., Yoshioka, M., Collins, W., Conley, A., Fillmore, D., and Coleman, D.: Climate response and radiative forcing from mineral aerosols during the glacial maximum, pre-industrial, current and doubled-carbon dioxide climates, Geophysical Research Letters, 33, L20 705, doi $10.1029 / 2006$ GL026126, 2006.

Mariotti, V., Paillard, D., Roche, D. M. Bouttes, N., and Bopp, L.: Simulated Last Glacial Maximum $\Delta^{14} C_{a t m}$ and the deep glacial ocean carbon reservoir, Radiocarbon, 55, 1595-1602, doi 10.2458/azu_js_rc.55.16295. 2013.

Mariotti, V., Paillard, D., Bopp, L., Roche, D. M., and Bouttes, N.: A coupled model for carbon and radiocarbon evolution during the last deglaciation, Geophysical Research Letters, 43, 1306-1313, doi:10.1002/2015GL067489, 2016.

Masarik, J. and Beer, J.: Simulation of particle fluxes and cosmogenic nuclide production in the Earth's atmosphere, Journal of Geophysical Research, 104, 12 099-12 111, doi 10.1029/1998JD200091. 1999.

Muscheler, R., Beer, J., Wagner, G., Laj, C., Kissel, C., Raisbeck, G. M., Yiou, F., and Kubik, P. W.: Changes in the carbon cycle during the last deglaciation as indicated by the comparison of ${ }^{10} \mathrm{Be}$ and ${ }^{14} \mathrm{C}$ records, Earth and Planetary Science Letters, 219, 325-340, doi $10.1016 / \mathrm{S} 0012-821 \mathrm{X}(03) 00722-2,2004$.

Muscheler, R., Beer, J., Kubik, P. W., and Synal, H.-A.: Geomagnetic field intensity during the last 60,000 years based on ${ }^{10} \mathrm{Be}$ and ${ }^{36} \mathrm{Cl}$ from the Summit ice cores and ${ }^{14}$ C, Quaternary Science Reviews, 24, 1849-1860, doi:10.1016/j.quascirev.2005.01.012. 2005.

Okazaki, Y., Timmermann, A., Menviel, L., Harada, N., Abe-Ouchi, A., Chikamoto, M. O., Mouchet, A., and Asahi, H.: Deepwater Formation in the North Pacific During the Last Glacial Termination, Science, 329, 200-204, doi $10.1126 /$ science.1190612 2010.

Peterson, C. D., Lisiecki, L. E., and Stern, J. V.: Deglacial whole-ocean $\delta^{13} \mathrm{C}$ change estimated from 480 benthic foraminiferal records, Paleoceanography, 29, 549-563, doi:10.1002/2013PA002552, 2014.

Reimer, P. J., Bard, E., Bayliss, A., Beck, J. W., Blackwell, P. G., Ramsey, C. B., Buck, C. E., Cheng, H., Edwards, R. L., Friedrich, M., Grootes, P. M., Guilderson, T. P., Haflidason, H., Hajdas, I., Hatté, C., Heaton, T. J., Hoffmann, D. L., Hogg, A. G., Hughen, K. A., Kaiser, K. F., Kromer, B., Manning, S. W., Niu, M., Reimer, R. W., Richards, D. A., Scott, E. M., Southon, J. R., Staff, R. A., Turney, C. S. M., and van der Plicht, J.: INTCAL13 and MARINE13 radiocarbon age calibration curves 0-50,000 years cal BP, Radiocarbon, 55, Nr. 4, 1869-1887, doi:10.2458/azu_js_rc.55.16947, 2013.

Schilt, A., Baumgartner, M., Blunier, T., Schwander, J., Spahni, R., Fischer, H., and Stocker, T. F.: Glacial-Interglacial and Millennial Scale Variations in the Atmospheric Nitrous Oxide Concentration during the last 800,000 Years, Quaternary Science Reviews, 29, 182-192, doi $10.1016 /$ j.quascirev.2009.03.011, 2010.

Schmitt, J., Schneider, R., Elsig, J., Leuenberger, D., Lourantou, A., Chappellaz, J., Köhler, Joos, F., Stocker, T. F., Leuenberger, M., and Fischer, H.: Carbon Isotope Constraints on the Deglacial $\mathrm{CO}_{2}$ Rise from Ice Cores, Science, 336, 710-714, doi 10.1126/science.1217161 2012.

Schmittner, A., Urban, N. M., Shakun, J. D., Mahowald, N. M., Clark, P. U., Bartlein, P. J., Mix, A. C., and Rosell-Melé, A.: Climate Sensitivity Estimated from Temperature Reconstructions of the Last Glacial Maximum, Science, 334, 1385-1388, doi 10.1126/science.1203513 2011.

Shaffer, G., Malskær Olsen, S., and Pepke Pedersen, J.: Presentation, calibration and validation of the low-order, DCESS Earth System Model (Version 1), Geoscientific Model Development, 1, 17-51, doi:10.5194/gmd-1-17-2008, 2008. 
Shakun, J., Clark, P. U., He, F., Marcott, S. A., Mix, A. C., Liu, Z. Y., Otto-Bliesner, B., Schmittner, A., and Bard, E.: Global warming preceded by increasing carbon dioxide concentrations during the last deglaciation, Nature, 484, 49-54, doi 10.1038/nature10915. 2012.

Sigman, D. M. and Boyle, E. A.: Glacial/interglacial variations in atmospheric carbon dioxide, Nature, 407, 859-869, doi 10.1038/35038000 2000 .

5 Sikes, E., Samson, C., Guilderson, T., and Howard, W.: Old radiocarbon ages in the southwest Pacific Ocean during the last glacial period and deglaciation, Nature, 405, 555-559, doi $10.1038 / 35014581.2000$.

Skinner, L. C., Fallon, S., Waelbroeck, C., Michel, E., and Barker, S.: Ventilation of deep Southern Ocean and deglacial CO ${ }_{2}$ rise, Science, 328(5982), 1147-1151, doi 10.1126/science.1183627, 2010.

Thornalley, D. J. R., Barker, S., Broecker, W. S., Elderfield, H., and McCave, I. N.: The deglacial evolution of North Atlantic deep convection, Science, 331, 202-205, doi 10.1126/science.1196812, 2011.

Toggweiler, J. R. and Russel, J.: Ocean circulation in a warming climate, Nature, 451, 286-288, doi 10.1038/nature06590 2008.

Vance, D., Teagle, D. A. H., and Foster, G. L.: Variable Quaternary chemical weathering fluxes and imbalances in marine geochemical budgets, Nature, 458, 493-496, doi:10.1038/nature07828, 2009.

Watson, A. J. and Naveira Garabato, A. C.: The role of Southern Ocean mixing and upwelling in glacial-interglacial atmospheric $\mathrm{CO}_{2}$ change, Tellus, 58B, 73-87, doi $10.1111 / \mathrm{j} .1600-0889.2005 .00167 . \mathrm{x} 2006$.

Winckler, G., Anderson, R. F., Fleisher, M. Q., McGee, D., and Mahowald, N.: Covariant Glacial-Interglacial Dust Fluxes in the Equatorial Pacific and Antarctica, Science, 320, 93-96, doi 10.1126/science.1150595, 2008.

Zech, R.: A permafrost glacial hypothesis - Permafrost carbon might help explaining the Pleistocene ice ages, Quaternary Science Journal, 61 (1), 84-92, doi $10.3285 /$ eg.61.1.07. 2012.

20 Zhang, Q. L., Chang, T. L., and Li, W. J.: A Calibrated Measurement of the Atomic-weight of Carbon, Chinese Science Bulletin, 35, 290-296, 1990. 